\title{
ДОСЛІДЖЕННЯ НЕІНВАЗИВНОГО МЕТОДУ ВИЗНАЧЕННЯ ЦУКРУ КРОВІ людини
}

Національний технічний університет України «Київський політехнічний інститут»

\begin{abstract}
Запропоновано метод неінвазивного визначення цукру крові людини шляхом вимірювання стохастичних характеристик води, в яку занурюється палець пацієнта. Проведено вимірювання концентрації глюкози крові пацієнтів

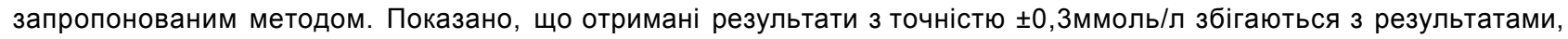
отриманими традиційним методом за допомогою глюкометра.
\end{abstract}

Ключові слова: цукровий діабет, стохастичні характеристики водних розчинів, вимірювання глюкози в крові.

\section{ИССЛЕДОВАНИЯ НЕИНВАЗИВНОГО МЕТОДА ОПРЕДЕЛЕНИЯ САХАРА КРОВИ ЧЕЛОВЕКА}

\author{
П. П. Лошицкий, Д. Ю. Минзяк \\ Национальный технический университет Украины «Киевский политехнический институт» \\ Обоснован метод неинвазивного определения сахара крови человека путем измерения стохастических характе- \\ ристик воды, в которую помещается палец пациента. Проведены измерения концентрации глюкозы крови паци-

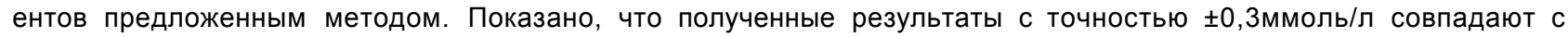 \\ результатами, полученными традиционным методом с помощью глюкометра.
}

Ключевые слова: сахарный диабет, стохастические характеристики водных растворов, измерение глюкозы в крови.

\section{RESEARCH NONINVASIVE METHODS FOR DETERMINING BLOOD SUGAR OF HUMAN}

\author{
P. P. Loshytskyi, D. Yu. Mynzyak \\ National Technical University of Ukraine «Kyiv Polytechnic Institute»
}

Non-invasive method of determining human blood sugar is explained by measuring stochastic characteristics of the water. Measurements of blood glucose of patients by the proposed method is shown by results obtained with an accuracy of $\pm 0,3 \mathrm{mmol} / \mathrm{l}$ coincide with the results obtained by a conventional method using a glucometer.

Key words: diabetes mellitus, stochastic characteristics, aqueous solutions.

Вступ. Цукровий діабет - це хронічне ендокринне захворювання, пов'язане з порушенням обміну речовин в організмі, що призводить до виникнення гіперглікемії. Контроль рівня цукру крові дозволяє міняти стратегію лікування. Крім того, регулярний контроль рівня цукру крові може допомогти знизити ризик розвитку довгострокових ускладнень [I].

Традиційний метод визначення рівня цукру крові полягає в проколюванні пальця, розміщенні краплі крові на тест-смужці та проведення вимірювання за допомогою глюкометра, чи вимірювання за іншими методиками. Однак при заборі крові, особливо при масових обстеженнях, виникає ризик зараження цілим рядом захворювань, що передаються через кров, наприклад, СНІД, гепатит та інші. До теперішнього часу не вдалося розробити досить ефективний неінвазивний і безпечний метод визначення рівня цукру крові.

Метою роботи є подальші дослідження щодо розроблення неінвазивного методу визначення цукру крові людини.

Обгрунтування методу.

I. Спонтанні коливання водних розчинів

При аналізі фізичних основ, які можуть бути використані в розробці неінвазивного методу визначення

(ㄷ П. П. Лошицький, Д. Ю. Минзяк 
концентрації глюкози в крові пацієнта, необхідно звернути увагу на властивості води і водних розчинів, i насамперед на їх структурну динаміку.

Одним 3 показників, що відображають структурні параметри розчинів, є світлорозсіювання. У роботах $[2,3]$ показано, що у воді, водних розчинах електролітів і білків спостерігаються спонтанні коливання рівня розсіяного світла, що відображають динаміку структури досліджуваних середовищ. У той же час, рідини іншого типу, наприклад гліцерин і ксилол, не мають подібних коливань. У роботі [4] показано, що амплітуда спонтанних коливань водних розчинів пов'язана з припливними явищами і корелює з фазами Місяця. У роботах $[5,6]$ методом візуалізації динаміки руху дисперсних фаз визначені чисельні і масові розподілення часток за розмірами (розмірні спектри) та їх розподіл за площею поверхні. Також було показано, що не тільки частинки речовини з розмірами I-10 мкм, а й субмікронні фракції здійснюють не броунівський, а впорядкований рух поблизу розділу фаз (повітря - вода) при товщині шару до 10 см. Ступінь впорядкованості руху залежить від складу розчину. Припущено, що у водних розчинах присутні надмолекулярні структури з дальнім порядком взаємодії, що призводить до значного збільшення часу броунівської релаксації. Періодичні флуктуації структурних дефектів у водних розчинах можуть призводити до впорядковування хаотичного броунівського руху, що було виявлено за порушенням гаусівського розподілу часток суспензії. При цьому експериментально показано, що усунення неоднорідності води за ізотопним складом призводить до збільшення іiі однорідності за структурою на субміліметровому рівні розмірів. Такі супранадмолекулярні комплекси можуть грати роль напрямних при русі дисперсної фази за наявності значного числа іонізованих і поляризованих груп, які забезпечують гідрофільність.

Для розуміння основних закономірностей розглянемо максимально просту модель руху частинок під дією теплових флуктуацій [7]. Розглядається броунівська частинка в одному вимірі $з$ координатою $x(i)$ і масою т, що підпорядковується рівнянню руху Ньютона.

$$
m \ddot{x}(t)+V^{\prime}(x(t))=-\eta \dot{x}(t)+\xi(t) .
$$
де $V^{\prime}(x(t))$-періодичний потенціал з періодом $L$,

$$
V(x+L)=V(x)
$$

Ліва частина в (1) являє собою детерміновану, консервативну частину динаміки частинки, тоді як права частина враховує вплив теплового середовища. Розсіювання енергії моделюється у вигляді в'язкого тертя з коефіцієнтом тертя $\eta$ і випадкових флуктуа- ційних сил у вигляді теплового шуму $\xi(\mathrm{t})$. Ці два ефекти не є незалежними один від одного, так як вони мають однакове походження, а саме взаємодію частинки з великою кількістю мікроскопічних ступенів свободи навколишнього середовища.

Незалежно від будь-яких мікроскопічних деталей $\varepsilon(\mathrm{t}) \epsilon$ гаусівським білим шумом 3 нульовим середнім

$$
<\xi(\mathrm{t})>=0,
$$

задовольняє флуктуаційно-дисипативному співвідношенню [8]

$$
\langle\xi(t) \xi(s)\rangle=2 \eta k_{B} T \delta(t-s)
$$

де $k_{B}$ - стала Больцмана. $2 \eta k_{B} T-$ інтенсивність шуму або сила шуму, с (0 - дельта-функція Дірака.

Відзначимо, що тільки властивість 3 коефіцієнта тертя частинки входить до характеристики шуму, яке можна розглядати як силу зв'язку 3 навколишнім середовищем. Для дуже невеликих систем передбачається, що теплові флуктуації відіграють помітну роль, а динаміка (1) передемпфірована, тобто інерційний член незначний. Таким чином, приходимо до «мінімальної» моделі тріскачки (храповика) Смолуховського-Фейнмана:

$$
\eta \dot{x}(t)=-V^{\prime}(x(t))+\xi(t) .
$$

Згідно (3), гаусівський білий шум $\xi(\mathrm{t})$ некорельований у часі, тобто він задається незалежними дискретними гаусівськими випадковими числами в будьякий час 1

Розглянемо статистичний ансамбль стохастичних процесів, що належать до незалежних реалізацій випадкових флуктуацій Сф. Відповідна щільність ймовірності в просторі в момент часу I описує розподіл броунівських частинок і їі слід розглядати як усереднений ансамбль у вигляді

$$
P(x, t):=\langle\delta(x-x(t))\rangle .
$$

Безпосереднім наслідком цього визначення $\epsilon$ нормалізація

$$
\int_{-\infty}^{\wedge} d x P(x, t)=1
$$

Іншим тривіальним наслідком $є$ те, що $\mathrm{P}(\mathrm{x}, \tau)>0$ для всіх $x$ i і Для визначення тимчасової еволюції розглянемо рівняння Фоккера-Планка для цього випадку $[91$.

$$
\frac{\partial}{\partial t} P(x, t)=\frac{\partial}{\partial x}\left\{\frac{V^{\prime}(x)}{\eta} P(x, t)\right\}+\frac{k_{B} T}{\eta} \frac{\partial^{2}}{\partial x^{2}} P(x, t),
$$

де перший доданок у правій частині називають "дрейфовим", а другий - «дифузійним» членами.

Кількісно, основний інтерес в розглянутих системах $\epsilon$ струм частинок $\langle\dot{x}\rangle$ : залежний від часу ансамблів середніх за швидкостями

$$
\langle\dot{x}\rangle:=\langle\dot{x}(t)\rangle \text {. }
$$


Густина імовірності $P(x, t)$ містить повну інформацію про систему, в тому числі і про потік $\langle\dot{x}\rangle$. Визначимо його наступним чином. Зв'язок між $\langle\dot{x}\rangle$ i $P(x, t)$ встановлюється шляхом усереднення в (5) і з урахуванням (3), тобто $\langle\dot{x}\rangle=-\left\langle V^{\prime}(x(t))\right\rangle / \eta$.

Так як середнє по ансамблю визначається через густину імовірності $P(x, t)$, встановлюємо зв'язок між $(\dot{x})$ і $P(x, t)$ :

$$
\langle\dot{x}\rangle=-\int_{-\infty}^{\infty} d x \frac{V^{\prime}(x)}{\eta} P(x, t) .
$$

Іншими словами, щоб відповісти на питання скільки необхідно в потоці частинок х , досить вирішити рівняння Фоккера-Планка з періодичною межею (та початковими умовами).

Отже, потоки в рідині, що визначають динаміку системи, залежать від мас «часток», розмірів, температури, в'язкості, періодичності та величин потенціалів (у тому числі і хаотичних), тобто несуть повну інформацію рідкого середовища з усіма його особливостями. Це означає, що дослідження спектрів стохастичних процесів у рідкому середовищі дозволить визначити різні характеристики середовища, в тому числі і концентрації компонентів розчину.

\section{2. Стохастична синхронізація}

Явище вимушеної стохастичної синхронізації було виявлено в роботі [10] при чисельному дослідженні процесів просторового розвитку турбулентності в «потоковій» динамічній системі - напівнескінченному ланцюжку, односпрямовано - пов'язаних тотожних автогенераторів. Було встановлено, що періодичні на початку системи коливання при поширенні уздовж ланцюжка перетворюються на квазіперіодичні а потім у стохастичні [11].

Той факт, що спостерігається стаціонарність цих характеристик уздовж ланцюжка, якраз іє проявом вимушеної стохастичної синхронізації коливань: кожен наступний автогенератор відтворює стохастичний сигнал, що надходить на його вхід.

Взаємна стохастична синхронізація коливань спостерігалася в системі дисипативно-пов'язаних генераторів з хаотичною індивідуальною динамікою [12]. Динаміка кожного $з$ двох параметрично порушуваних ангармонічних осциляторів описується рівнянням:

$$
\frac{d^{2} x_{1,2}}{d t^{2}}+k_{1,2} \frac{d x_{1,2}}{d t}+(1+q \cos \Omega t) x_{1,2}+x_{1,2}^{3}=0
$$

де $x$ - зміщення, $\kappa$ - коефіцієнт опору (тертя), q величина амплітуди параметричного збудження, а,$\Omega$ - його кругова частота.

У широкій області значень параметрів q, спостерігаються хаотичні коливання к для кожного осциля- тора, властивості яких добре вивчені [13] і відтворені в аналоговому експерименті.

Для двох пов'язаних генераторів система рівнянь має вигляд:

$$
\begin{aligned}
& \frac{d x_{1}}{d t}=y_{1}, \\
& \quad \frac{d y_{1}}{d t}=-^{\prime \prime} \quad\left(1+q \operatorname{CO} 8+{ }^{\prime 2}\right)-c\left(y^{\wedge}-y_{2}\right), \\
& \frac{d x_{2}}{d t}=y_{2}, \\
& \frac{d y_{2}}{d t}=-k_{2} y_{2}-x_{2}\left(1+q \cos \theta+x_{2}^{2}\right)+c\left(y_{1}-y_{2}\right), \\
& \frac{d \theta}{d t}=\Omega .
\end{aligned}
$$

Фізична природа стохастичної синхронізації пов'язана $з$ дисипативним характером взаємодії між елементарними генераторами, вона зменшує неузгодженість у поведінці індивідуальних генераторів.

Вода і водні розчини не тільки є основними компонентами живої матерії, а й мають багато спільних 3 нею властивостей. Особливо багато однакових властивостей повинні мати водні розчини і мозок. Проводячи спектральний аналіз коливань біострумів мозку з високим ступенем дозволу, Н. Вінер виявив, що спектр поблизу частоти 10 Гц має особливу структуру: по перше - дуже вузька лінія в центрі спектра і по-друге - ця лінія піднімається з поглиблення [14]. Пояснення того, чим викликана така будова спектра, було наступне: у мозку є осцилятори деякого роду, які в сукупності утворюють більш добротний осцилятор. Частоти цих різних осциляторів (а їх можна розглядати як нелінійні осцилятори) пов'язані між собою. Має існувати затягування частот, які лежать поблизу центральної (рис. 1).

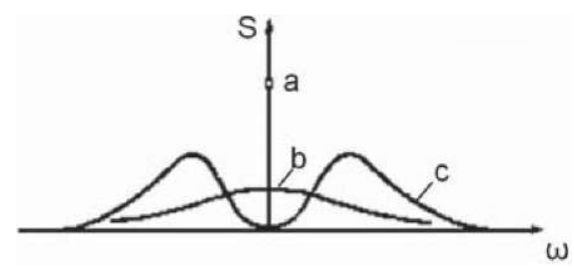

Puc. I. Спектр частот біострумів мозку людини: $\mathrm{a}, \mathrm{b}, \mathrm{c}$ - складові спектра частот.

Дане положення дозволяє припустити, що при дослідженні стохастичних характеристик водних розчинів, необхідно використовувати шумові джерела для стохастичної синхронізації спонтанних коливань розчинів, що дозволить збільшити точність визначення спектрів. 


\section{3. «Пам'ять» води}

Для неінвазивного визначення характеристик розчинів, зокрема концентрації глюкози, необхідно використовувати властивість води сприймати і налаштовуватися на зовнішні коливання інших водних розчинів, синхронізуватися з ними [15].

У роботі [ 16] показано, що якщо воду обробити фізичним чинником вкрай низької інтенсивності (наприклад електромагнітним полем) і помістити в неї діелектричну посудину з водним розчином живих об'єктів, наприклад бактерій, то ці живі об'єкти будуть мати такі ж характеристики, які вони мали б при безпосередньому впливі фізичного чинника. І навпаки, якщо в посудину з водою помістити діелектричну ємність з розчином, обробленим фізичним чинником, то параметри води стануть такими ж, як і при обробці фізичним чинником. Отже, на досліджуваний розчин необхідно впливати зовнішнім електромагнітним полем вкрай низької інтенсивності не тільки для підвищення точності визначення параметрів, а й для індукування коливань у воді, в яку поміщається досліджуваний розчин.

\section{Матеріали та обладнання}

Дослідження властивостей водних розчинів проводилися за допомогою розробленого пристрою, який дозволяє вимірювати флуктуації диференціальної температури з точністю $0,03{ }^{\circ} \mathrm{C}$. Температура обрана як інтегральний чинник, зміни якої пов'язані з коливаннями структур рідини та мікропотоків. Характеристики та детальна методика вимірювань апаратурного комплексу наведена в роботі [17].

За результатами вимірювань флуктуацій температури, вимірюваної протягом 30 хвилин при впливі зовнішнього чинника визначалися значення величин функції автокореляції і коефіцієнтів перетворення Фур'є дисперсії диференціальної температури кожного 3 випадкових процесів. Результати оброблялися за стандартною методикою в пакеті М-bаЬ.

Для досліджень використовувалася дистильована вода напівпровідникової частоти не менше $99 \%$ та сироватка крові людини з різним вмістом глюкози.

\section{Результати дослідження}

Перш за все проводилися модельні дослідження визначення концентрації безпосередньо в об'ємі досліджуваної речовини, в якості котрих використовували розчини глюкози різних концентрацій [18]. Ці дослідження свідчать, що за стохастичними характеристиками можливо встановити концентраційні залежності.

На наступному етапі досліджень визначали концентрації розчинів в закритому об'ємі без доступу до самого розчину [19].
Для досліджень неінвазивного визначення концентрації глюкози в крові людини на першому етапі створювалася база еталонних кривих, для якої використовувалася плазма крові людини з різним вмістом цукру. Еталонні криві формувалися наступним чином. Відбиралася сироватка крові з вмістом глюкози від 4 ммоль/л до 12 ммоль/л, для якої проводилися вимірювання флуктуацій диференціальної температури під час НВЧ-опромінення. За результатами вимірювань визначалися значення величин функції автокореляції та коефіцієнтів перетворення Фур'є дисперсії диференціальної температури для кожної проби сироватки.

Після проведення досліджень на розчинах глюкози і сироватки крові були проведені експерименти по неінвазивному вимірюванню концентрації глюкози крові людини. Для цього проводилися вимірювання шумів диференціальної температури дистильованої води, в яку занурюється палець пацієнта, що дозволяє уникнути необхідності забору крові і, відповідно, можливості зараження пацієнта. На рисунку 2 наведена схема неінвазивного вимірювання глюкози в крові людини.

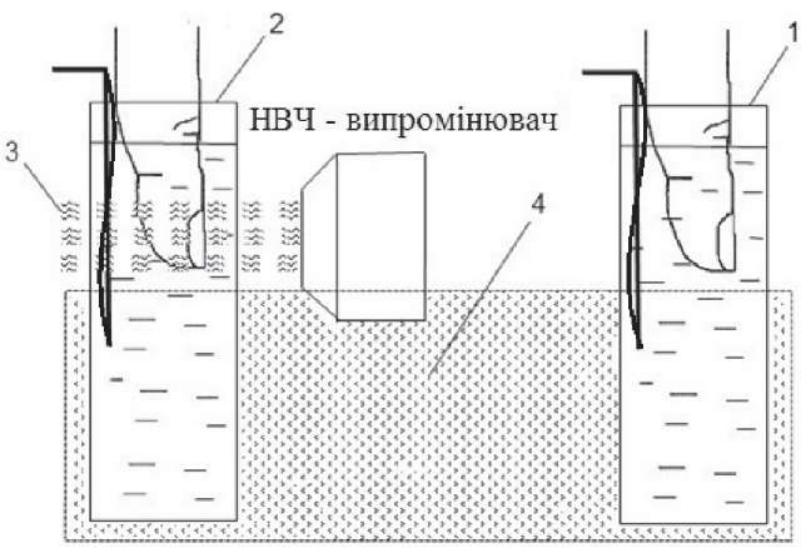

Puc. 2. Схема неінвазивного визначення концентрації цукру в крові людини.

Палець кожної з рук занурювався у дистильовану воду, яка перебувала в однакових пробірках (1 і 2 на рис. 2). Між пробірками знаходиться теплоізоляційна пінопластова прокладка (4). Вимірювальні термопари поміщалися у воду та знаходилися на однаковій відстані від пальців. Одна з пробірок з водою, в якій знаходився палець піддавалася впливу зовнішнім фізичним чинником (НВЧ - випромінюванням) вкрай низької інтенсивності протягом фіксованого часу.

Отримані значення відносних частот, на яких спостерігалися піки коефіцієнтів Фур'є і відносних періодів автокореляційної функції порівнювалися з попередньо отриманими еталонними значеннями цих са- 
мих величин для плазми крові відповідних концентрацій, по яких і визначалася концентрація глюкози в крові людини. Для перевірки достовірності отриманих результатів відразу після проведення вимірювань запропонованою методикою, пацієнти визначали рівень цукру у своїй крові за допомогою портативного глюкометра «One Touch Select» [20]. Порівняльні результати деяких вимірювань наведені в таблиці I.

Таблиця І. Порівняльні результати вимірювань концентрації глюкози крові людини

\begin{tabular}{|c|c|c|}
\hline \multirow[b]{2}{*}{$\begin{array}{c}\text { Номер } \\
\text { паціснта }\end{array}$} & \multicolumn{2}{|c|}{ Концентрація глюкози крові людини } \\
\hline & $\begin{array}{c}\text { результати вимірювань конщентрації глюкози в } \\
\text { крові людини, отримані глюкометром } \\
\text { "OneTouch Select", ммоль/л }\end{array}$ & $\begin{array}{c}\text { результати вимірювань концентрації глюкози } \\
\text { в крові людини, отримані неінвазивним } \\
\text { методом, ммоль/л }\end{array}$ \\
\hline 1 & 10.9 & 10.8 \\
\hline 2 & 7.7 & 7.5 \\
\hline 3 & 6.0 & 6.3 \\
\hline 4 & 5.5 & 5.5 \\
\hline 5 & 5.4 & 5.3 \\
\hline
\end{tabular}

Як бачимо з таблиці I, результати вимірювань концентрації глюкози крові людини, отримані розробленим методом та за допомогою глюкометра, відрізняються не більше ніж $\pm 0,03$ ммоль/л.

\section{Висновки}

1. Показано, що спонтанні коливання водних розчинів пов'язані не тільки з броунівським рухом рідини, а і $з$ потоками, викликаними упорядкованим рухом рідини, обумовленим ефектом тріскачки.

2. Вимірювання стохастичних величин пов'язане 3 великими похибками, зумовленими «розмитістю» вимірюваних величин. Проте, в деяких випадках,

\section{Література}

1. Радкевич В. Сахарный диабет / В. Радкевич. - М. : Грэгори, $1998-316 \mathrm{c}$.

2. Черняков Ф. Р. Колебания светорассеяния в водных растворах белков / Ф. Р. Черняков // Биофизика. - 1986. - Т. 31 , № 4. - C. 596-609.

3. Черняков Ф. Р. Влияние некоторых физических факторов на колебания светорассеяния в воде и водных растворах биополимеров / Ф. Р. Черняков // Биофизика. - 1990. T. 35, №a 5. - C. 711-714.

4. Реакція води на природні та штучні фізичні фактори наднизької інтенсивності / А. Б. Загородній, П. П. Лошицький, В. М. Мамаєв [та ін.] // Медична інформатика та інженерія. - 2008. - №a 3. - С. 27-32.

5. Смирнов А.Н., Лапшин В.Б., Балашев А.В., Попов П.И., Лебедев И.М., Сыроешкин А.В. Кооперативное анизотропное движение дисперсной фазы в водных растворах // Электронный журнал «Исследовано в России». 2004, http: // zhumal.ape.relarn.ru/2004/039.pdf.

6. Сыроешкин А. В., Смирнов А. Н., Гончарук В. В., Успенская Е. В., Николаев Г. М., Попов П. И., Кармазина Г. В., Самсони-Тодоров А. О., Лапшин В. Б. Вода как гетерогенная структура // Электронный журнал «Исследовано в використовуючи стохастичну синхронізацію, похибки можуть бути зведені до мінімуму.

3. Розроблено метод неінвазивного вимірювання цукру крові людини і проведено порівняння точності запропонованого і традиційного методів. Представлені результати вимірювань концентрації глюкози в крові людини, отримані запропонованим неінвазивним методом, відрізняються на $\pm 0,3$ ммоль/л від результатів, що вимірювались портативним глюкометром. Точність запропонованого методу визначається точністю калібрування еталонних зразків розчинів.

России». 2006, http://zhurnal.ape.relarn.ru/articles/2006/ 088.pdf

7. Reimann P. Brownian motors: noisy transport far from equilibrium/P. Reimann // Physics Reports. - 2002. - Vol. 361. - P. 57-265.

8. Callen H. B. Irreversibility and generalized noise / H. B. Callen, T. A. Welton// Phys. Rev. - 1951. -Vol. 82. - P. 34.

9. Risken H. The Pokker - Plank Equation. - Berlin, Springer, 1984.

10. Динамическая модель пространственного развития турбулентности / А. В. Гапонов-Грехов, М. И. Рабинович, И. М. Старобинец // Письма в ЖЭТФ. 1984. - Т. 39, Вып.12. - С. 561 - 564.

11. Арансон И. С., Гапонов - Грехов А. В., Рабинович М. И., Старобинец И. М. Структурные аттракторы и пространственное развитие турбулентности в потоковых системах // ЖЭТФ - 1986. - т. 90, вып.5. - С. 1707-1718.

12. Афраймович В. С. Стохастическая синхронизация колебаний в диссипативных системах / В. С. Афраймович, Н. Н. Веричев, М. И. Рабинович // Изв. ВУЗов. Радиофизика. - 1986. - Т. 29, № 9. - С. 1050-1060. 
13. Афраймович В. С. Критические точки и «фазовые переходы» в стохастическом поведении неавтономного ангармонического осциллятора / В. С. Афраймович, М. И. Рабинович, А. Д. Угодников // Письма в ЖЭТФ. - 1983. Т. 38, Вып. 2. - С. 64-67.

14. Винер Н. Нелинейные задачи в теории случайных процессов / Н. Винер. - М.: Изд.инлит, 1961. - 160 с.

15. Деклараційний патент на корисну модель № 4789 ВОШ13/00, А23Ь2/50 від 15.04.2004. Лошицький П. П., Косоголова Л. А., Попова Н. В., Шеверня О. М. Спосіб обробки дисперсної системи в розчині. Бюл. №№ 2 від 15.02.2005. 16. Лошицький П. П. Регулирование свойств водных растворов электромагнитным излучением / П. П. Лошицький, Д. Ю. Минзяк // Электроника и связь. - 2012. - № 4. C. 14-17.
17. Минзяк Д. Ю. Исследование температурных флуктуаций дистиллированной воды / Д. Ю. Минзяк // Электроника и связь. - 2008. - № 6. - С. 49 -53.

18. Лошицький П. П. дослідження концентраційних залежностей водних розчинів / П. П. Лошицький, Д. Ю. Минзяк // Медична інформатика та інженерія. - 2011. - № 2. C. 29-34.

19. Лошицкий П. П. Исследование возможностей использования электромагнитного излучения миллиметрового диапазона длин волн для дистанционного регулирования свойств водных растворов / П. П. Лошицкий, Д. Ю. Минзяк // Автоматизированные системы управления и приборы автоматики. - 2012. - $\mathrm{N}^{\circ} 158$. - С. 72-77.

20. O. Davies, L. Christopher, M. Alvarez-Icaza, Measurement of substances in liquids U.S. Patent 6,733,655, filed Mart 08. 2000 and issued May 11. 2004. 